\title{
Case Presentation: Delayed Puberty
}

\section{Saadi JS AlJadir*}

Department of Endocrinology, Iraq

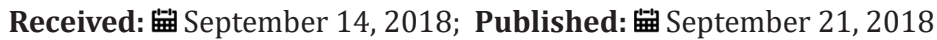

*Corresponding author: Saadi AlJadir, Senior consultant of Endocrinology, PO box 489, Nassiriya, Thi Qar, Iraq

\begin{abstract}
Delayed puberty is extremely common condition in both boys and girls. Delayed puberty is defined clinically as the absence of the first signs of physical and hormonal signs of pubertal development beyond the normal range for the population. In the developed world, this means the absence of breast development by age 12 years in girls, or absence of testicular enlargement by age 14 years in boys. However, there are racial and ethnic variations in the timing of puberty, such as earlier onset of puberty in African American girls compared with Caucasian counterparts (Table 1). Puberty may be delayed for several years and still occurs normally, in which case it is considered constitutional delay, a variation of healthy physical development. Delay of puberty may also occur due to undernutrition, chronic illness or systemic disease, or to defects of the reproductive system (hypogonadism) or the body's responsiveness to sex hormones. Any girl of 13 or boy of 14 years of age without signs of pubertal development falls more than 2.5 $\mathrm{SD}$ above the mean and is considered to have delayed puberty.
\end{abstract}

a. The normal variation in the age at which adolescent changes occur is so wide that puberty cannot be considered to be pathologically delayed until the menarche has failed to occur by the age of 18 or testicular development by the age of 20 .

b. A 20 years old student (Afghani; born in UAE), had been referred from RAK (May 2008) to Endocrine Clinic (Diabetes \& Endocrine Centre, FGH) for delayed puberty and features of underdevelopment of external genitalia, and diabetes.

\section{Introduction}

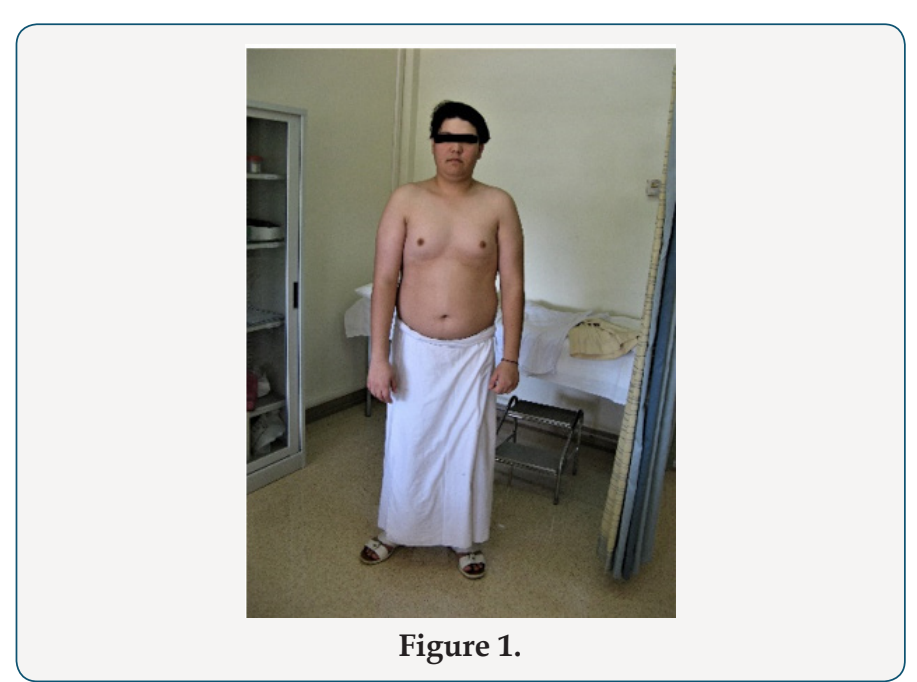

Young man 20 years of age (MMM Taher) with central obesity, gynecomastia, short upper body segment proportion; Eunuchoid body habitus with no facial hair, Patient is emotionally withdrawn, with clearly high-pitched voice. He was obviously uncooperative in communication and strongly disagreed picturing. Physically; lack of muscle bulk \& strength, he hasn't experienced erections or sexual desire, but no syncopal or dizziness spells. No skeletal abnormality, pigmentations. Gross Neurologic examination showed no gross abnormalities (Figures 1-4).

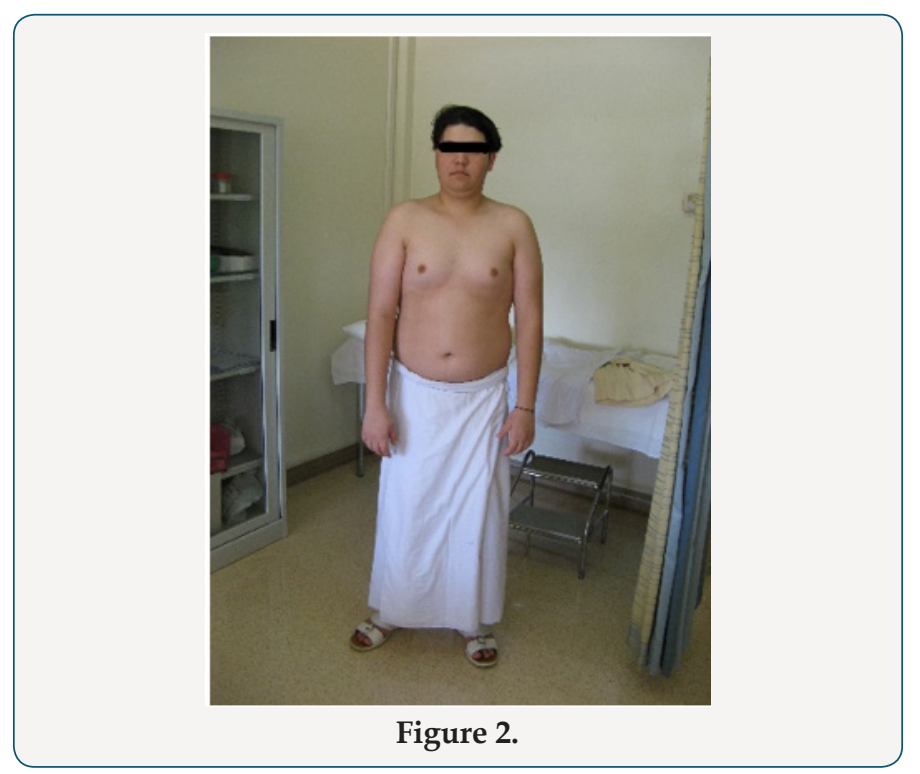



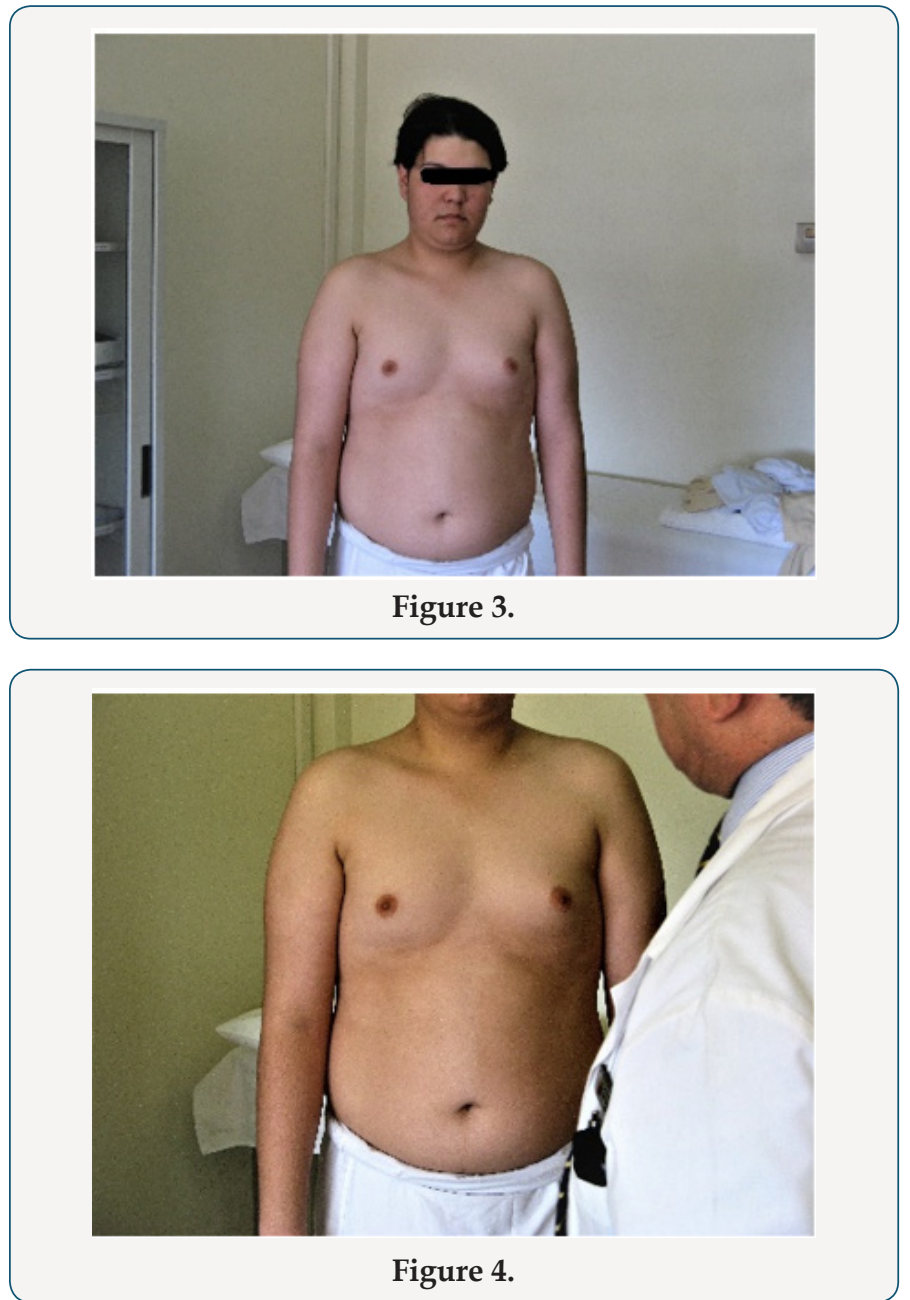

Family History: He has 2 brother and one sister all admitted as been normal growth and maturation, his parents were alive, his mother had T2 diabetes Mellitus.
i. $\quad$ BP $139 / 89 \mathrm{mmHg}$
ii. Height $176 \mathrm{~cm}$
iii. Weight 99kg; BMI 32
iv. $\quad$ WC $111 \mathrm{~cm}$
v. Blood Glucose (random): 201mg/dl
vi. Bilateral Breast enlargement; symmetrical
vii. No cervical or axillary LN, or any thyroid or breast mass
viii. No axillary hair
ix. Chest, no skeletal deformity
x. Heart; no added sound
xi. Abdomen, Liver was not enlarged, others unremarkable.
xii. His penis was remarkably small (micro phallus)
xiii. Testes small (Tanner 2-3) soft, rubbery

xiv. Scrotal skin was not dark, less rugous than usual.

xv. Pubic hair; villous and scanty.

The initial working diagnosis Hypogonadism most probably Kleinfelter's Syndrome.

a. Referred to Tawam Hospital (tertiary Centre) for Chromosomal karyotyping

b. Hormonal Profile

c. Blood chemistry \& blood picture

d. Ultrasound of Abdomen

\section{Hormonal Profile}

i. $\quad$ LH $1.290 \mathrm{mIU} / \mathrm{ml}$, 2nd sample: 1.062

ii. FSH $1.440 \mathrm{mIU} / \mathrm{ml}$, 2nd sample: 1.242

iii. Prolactin $4.150 \mathrm{ng} / \mathrm{ml}$, 2nd 4.428

iv. Testosterone (total) $0.310 \mathrm{ng} / \mathrm{ml}(2.800-11.100), 2 \mathrm{nd}$ sample 0.402

v. DHEAS $7.380 \mu \mathrm{mol} / \mathrm{L}(5.730-13.400)$

vi. $\quad$ SHBP $9.00 \mathrm{nmol} / \mathrm{L}$

vii. Free androgen Index 7.70nmol/L (men's range 14.8- 94.8, Females up to 11)

viii. Estradiol $11.4 \mathrm{pg} / \mathrm{ml}$ (N 10-40)

ix. TSH $2.354 \mathrm{mIU} / \mathrm{L}$

x. Cortisol (M) 13.4ug/dl (N 10-20)

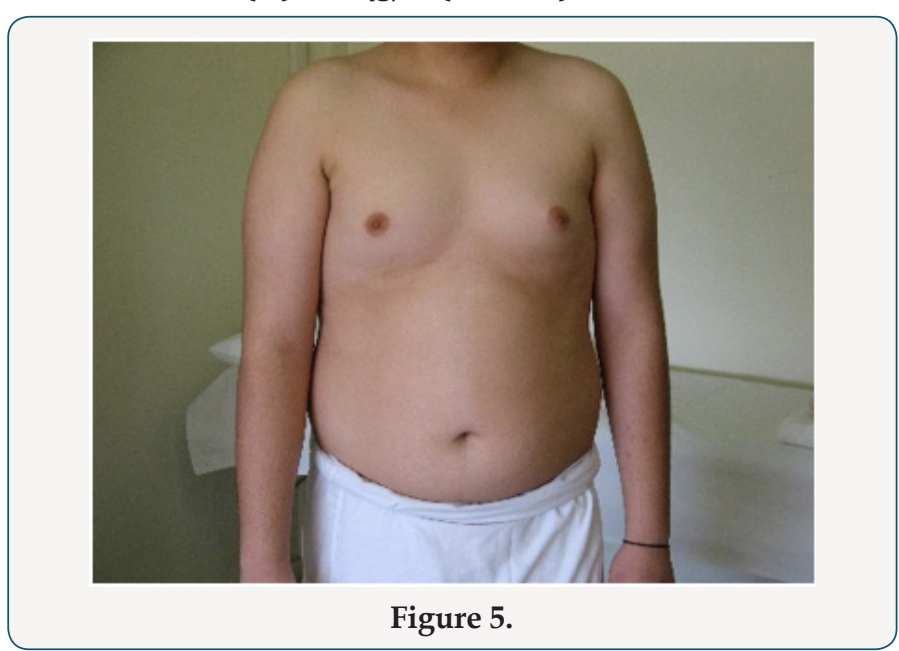

Ultrasound of Abdomen hadn't revealed any mass or abnormality. Blood Chemistry: LFT WNL, Urea, creatinine, electrolytes reported normal, urate $6.8 \mathrm{mg} / \mathrm{dl}$, FBS $(186 \mathrm{mg} / \mathrm{dl}$ ), TG 286, TC 262, HDL 38.68, LDL 112mg/dl, Blood picture: Hb 11.6 normochromic normocytic. WBC normal, 6 week later, we had received the chromosomal study; Karyotype 46 XY, Male Karyotype with no chromosomal abnormalities detected, therefore the working 
diagnosis had been changed to Idiopathic hypogonadotropic hypogonadism or Kallmann's Syndrome (Figures 5-8).
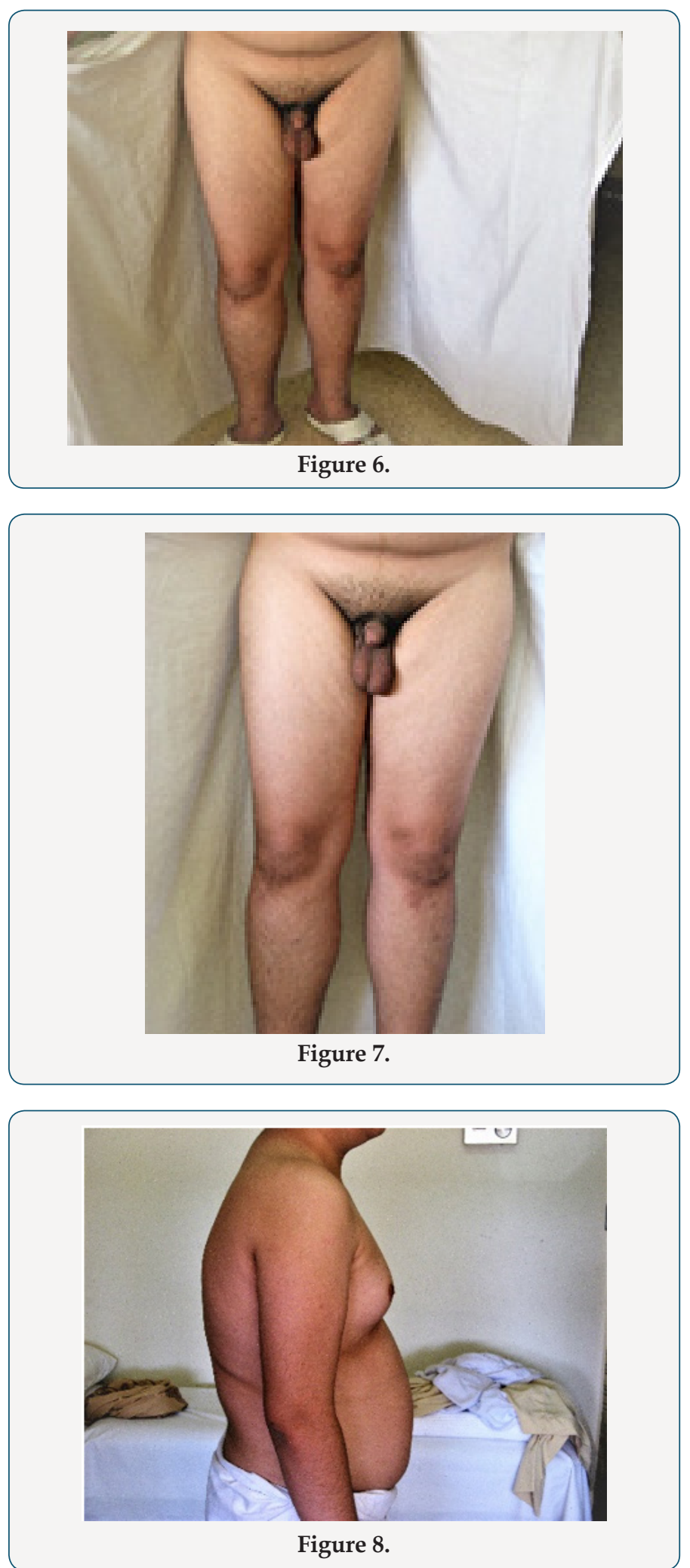

Assessment of the sense of smell is a frequently overlooked part of the clinical examination. The assessment is sometimes more complex than the examination of a 'single' cranial nerve and therefore not infrequently requires more than the simple question: 'Do you have any problems with your sense of smell?'. There is almost always a degree of uncertainty among exam candidates about how to proceed when the patient replies 'Yes' to this question, both in terms of immediate examination and further investigations. We asked the patient about his smell, he has definitive impairment of smell sensation as he experienced loss of many odors especially delaying in smelling his own cigarette smoke, as he compared with his friends' smell we referred him to ENT Specialist who confirmed his objective partial loss of smell, Hyposmia with no nasal disease reported, hearing was intact. MRI was performed and showed hypoplasia of the olfactory apparatus, with normal pituitary and brain structures. Approximately $75 \%$ of patients with KS have abnormal olfactory systems on MRI, including complete agenesis of olfactory bulbs and sulci, shallow olfactory sulci, or medial orientation of the olfactory sulci.

\section{Discussion}

Kallmann's syndrome was described in 1944 by Franz Josef Kallmann; a German-American Psychiatrist (\& Geneticist), long before a Spanish Physician Aureliano Maestri de San Juan had noticed a correlation between anosmia and hypogonadism in 1856 .

\section{Pathophysiology}

a) In KS, the GnRH neurons do not migrate properly from the olfactory placode to the hypothalamus during development.

b) The olfactory bulbs also fail to form or have hypoplasia, leading to anosmia or Hyposmia.

c) KS can be inherited as an X-linked recessive trait, in which case there is a defect in the KAL1 gene, which maps to chromosome Xp22.

d) KAL encodes a neural cell adhesion molecule, anosmin-1, Anosmin-1 is normally expressed in the brain, facial mesenchyme, mesonephros and metaphors.

i. It is required to promote migration of GnRH neurons into the hypothalamus, it also allows migration of olfactory neurons from the olfactory bulbs to the hypothalamus.

ii. An autosomal dominant gene on chromosome 8 \{8p12\} (KAL-2 or FGFR-1 (fibroblast growth factor receptor 1)) is thought to cause about $10 \%$ of additional autosomal cause of KS.

iii. Up to $30 \%$ of all $\mathrm{KS}$ cases can be linked to known genetic mutations.

A point should be considered:

The absent or decreased ability of the hypothalamus to secrete GnRH or of the pituitary gland to secrete LH and FSH leads to; Hypogonadotropic Hypogonadism. If the pituitary deficiency is limited to gonadotropins, patients are usually close to normal 
height for age until the age of the pubertal growth spurt, in contrast to the shorter patients with constitutional delay. Bone age is usually not delayed in childhood but does not progress normally after the patient reaches the age at which sex steroid secretion ordinarily stimulates maturation of the skeleton. However, if GH deficiency accompanies gonadotropin deficiency, severe short stature will result.

\section{Clinical features of KS}

a) KS is characterized by: Hypogonadotropic hypogonadism

b) Congenital (present from birth) anosmia, or Hyposmia

It can occasionally be associated with optic problems; colour blindness or optic atrophy, abnormal eye movements, nerve deafness, cleft palate, teeth maldevelopment

\section{Neurologic abnormalities}

Distinctive abnormal movement called bimanual synkinesis, in which the movements of one hand are mirrored by the other hand: bimanual synkinesis can make it difficult to do tasks that require the hands to move separately, such as playing a musical instrument, some cases had been reported to be associated with congenitally heart disease, septal defects, conductions defects or others.

\section{Skeletal abnormalities}

Only syndactyly, polydactyly, or camptodactyly were exclusively seen in the FGFR1/FGF8 group (and none of the other groups, including the RSV-negative group). Other skeletal anomalies such as scoliosis, kyphosis, excessive joint mobility, short fourth metacarpal bones, clinodactyly, foreshortened limb bones, and flat feet were seen in all groups.

a. cryptorchidism, renal agenesis (unilateral)

b. Males present with delayed puberty and may have micropenis (although congenital micro phallus is not present in most male KS cases).

c. Females present with delayed puberty (i.e. primary amenorrhea) and lack of secondary sex characteristics, such as breast development.

d. In women, late-onset KS can result in secondary amenorrhea.

e. A fraction of cases may present with post-pubertal onset, which results in a phenotypically normal penis in men with subsequent testicular atrophy and loss of some secondary sex traits. f. These men generally present with sexual impairment and low libido.

g. Anosmia may or may not be present in these individuals.

\section{Frequency}

Kallmann syndrome occurs more often in males than in females, with an estimated prevalence of 1 in 30,000 males and 1 in 120,000 females.

\section{Gender difference}

The male-to-female ratio ranges from 4:1 to 5:1.

The male-to-female ratio is approximately 2.5:1 among strictly familial Kallmann's syndrome and idiopathic hypogonadotropic hypogonadism cases.

\section{Medical treatment}

Androgen replacement in males with Kallmann syndrome or idiopathic hypogonadotropic hypogonadism restores libido, erectile function, and well-being. In addition, androgen replacement promotes the development of secondary sex characteristics (e.g., facial, axillary, and pubic hair), increases muscle strength improves bone density and may prevent osteoporosis. Either parenteral or transdermal testosterone is the drug of choice for androgen replacement. We had started Sustanon 250mg (Testosterone esters) by deep IM every 2 weeks, then titrated every 3 weeks, Metformin 2g/day, Lisinopril 10mg OD, advised for diet and life style with smoking cessation, he had been scheduled for DXA test after 3 months (Table 1).

Table 1: Normal Timing of Puberty both In Girls \& Boys.

\begin{tabular}{|c|c|}
\hline $\begin{array}{c}\text { North American, Indo-Iranian } \\
\text { (India, Iran), \& European Girls }\end{array}$ & $\begin{array}{c}\text { North American, Indo-Iranian, \& } \\
\text { European Boys }\end{array}$ \\
\hline Thelarche $10.5 \mathrm{y}(8-13 \mathrm{y})$ & $\begin{array}{r}\text { Testicular Enlargement } 11.5 \mathrm{y} \\
(9.5-13.5 \mathrm{y})\end{array}$ \\
\hline Pubarche $11 \mathrm{y}(8.5-13.5 \mathrm{y})$ & Pubic Hair $12 \mathrm{y}(10-14 \mathrm{y})$ \\
\hline Growth spurt $10-12.5 \mathrm{y}$ & Growth Spurt 14y \\
\hline Menarche $12.5 \mathrm{y}(10.5-14.5)$ & Completion of Growth $17 \mathrm{y}$ \\
\hline Adult Height reached $14.5 \mathrm{y}$ & \\
\hline
\end{tabular}

After 18 months of follow up, the patient had showed remarkable change in secondary sexual characters, muscles strength and selfesteem with more positive attitude toward communication and calmness. We couldn't arrange for family genetic testing due to financial obstacles and technical issue as this mandate advanced centre abroad. N.B this case had been presented (but not published) in Emirates Endocrine Club's meeting in Dubai May 2009 (Final Diagnosis: Kallmann's Syndrome). 


\section{(c) (P) This work is licensed under Creative}

Submission Link: Submit Article

DOI: 10.32474/OAJRSD.2018.01.000121

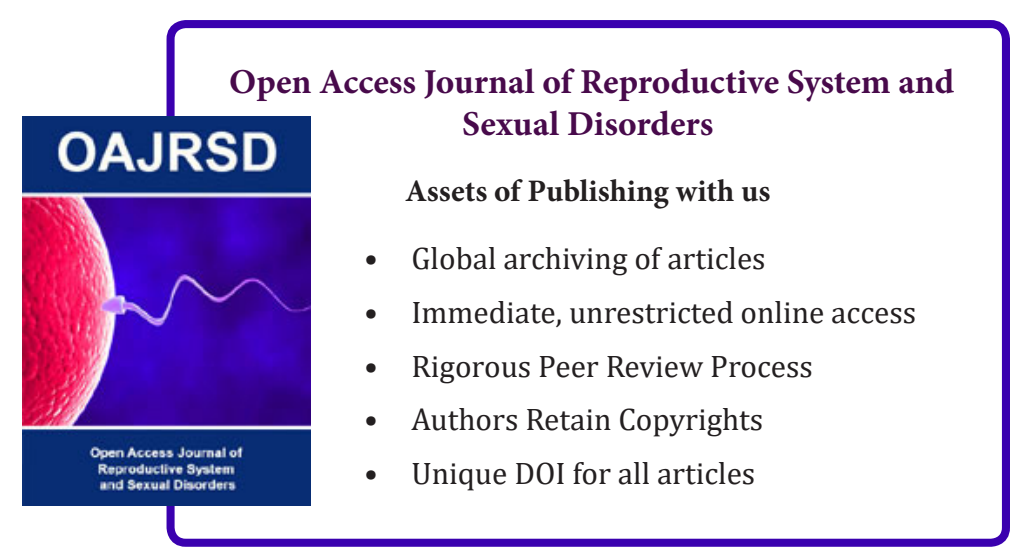

